\title{
O exercício farmacêutico na Bahia da segunda metade do século XIX
}

\section{Pharmaceutical practice in Bahia in the latter half of the $19^{\text {th }}$ century}

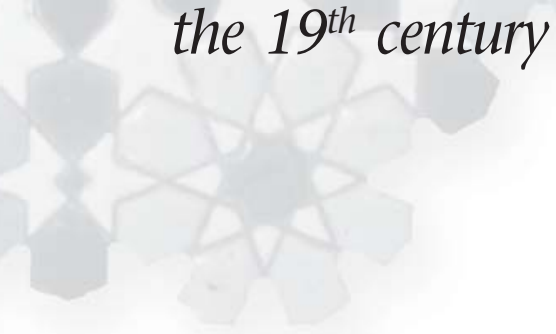

Tânia Salgado Pimenta

Pesquisadora da Casa de Oswaldo Cruz/Fundação Oswaldo Cruz Av. Brasil, 4036/404

21040-361- Rio de Janeiro - RJ - Brasil

taniaspimenta@coc.fiocruz.br

Ediná Alves Costa

Professora adjunta do Instituto de Saúde Coletiva Universidade Federal da Bahia

Rua Basílio da Gama, s/n

Campus Universitário Canela

40110-040 - Salvador - BA - Brasil edina@ufba.br

Submetido para publicação em maio 2007.

Aprovado para publicação em maio 2008.
PIMENTA, Tânia Salgado; COSTA, Ediná Alves. O exercício farmacêutico na Bahia da segunda metade do século XIX. História, Ciências, Saúde Manguinhos, Rio de Janeiro, v.15, n.4, out.-dez. 2008, p.1013-1023.

Resumo

Ao longo do Oitocentos, observa-se uma delimitação crescente dos ofícios relacionados às artes de curar no Brasil, enfatizando-se prerrogativas e responsabilidades. Verifica-se, na medicina acadêmica, progressiva distinção entre os que prescreviam e aqueles envolvidos na fabricação e comercialização de medicamentos. Procuramos investigar esse processo enfatizando o exercício farmacêutico na província da Bahia, na segunda metade do século XIX. Alguns dos aspectos que analisamos são as mudanças e permanências na legislação e a sua execução local, a relação dos farmacêuticos com as autoridades, os médicos e aqueles que atuavam ilegalmente fabricando e vendendo remédios sem autorização.

Palavras-chave: artes de curar; história da farmácia, história da saúde; século XIX; Bahia (Brasil).

\section{Abstract}

The nineteenth century brought the progressive demarcation of the professions devoted to the healing arts in Brazil, with a emphasis on rights and responsabilities. Academic medicine made a growing distinction between those who prescribed medicine and those who engaged in making or selling it. The article explores this process, with an emphasis on pharmaceutical practice in the province of Bahia in the latter half of the century. Within this context, it addresses changes and constancies in laws and in their local enforcement as well as relations between pharmacists, on the one hand, and, on the other, the government, physicians, and those who made or sold medicine illegally or without authorization.

Keywords: healing arts; history of pharmacy; history of health; nineteenth century; Bahia, Brazil. 
$\mathrm{E}$ ste trabalho faz parte de um projeto de pesquisa, em andamento, sobre história da saúde pública no Brasil, em que se pretende analisar as formas como os serviços relacionados ao controle de produtos e de atividades que pudessem afetar a saúde da população foram organizados ao longo dos séculos XIX e XX. ${ }^{1}$

A elaboração de remédios para aliviar o sofrimento e curar moléstias constitui aspecto fundamental das artes de curar. No Brasil do século XIX, era comum que as pessoas que desempenhavam essa atividade e costumavam vender os produtos que dela resultavam também diagnosticassem e prescrevessem o tratamento. Não foram poucos os farmacêuticos que obtiveram autorização para exercer 'medicina prática' ou para 'curar de medicina'. Essas licenças eram concedidas pela Fisicatura-mor (1808-1828), órgão do governo com sede no Rio de Janeiro, responsável pela regulamentação e fiscalização das atividades terapêuticas, mas observa-se que apenas uma pequena parte daqueles que exerciam práticas de cura se oficializavam de acordo com o alvará de 22 de janeiro de 1810, que "dá Regimento aos Delegados do Phisico-Mór e estabelece providências sobre a saúde pública".

Ao longo do Oitocentos, observa-se uma delimitação cada vez maior dos ofícios relacionados às artes de curar, procurando-se enfatizar suas prerrogativas e responsabilidades. Tal mudança insere-se no processo de institucionalização da medicina e reorganização do quadro oficial dessas artes, identificado no período (Pimenta, 1998).

Enquanto nas terapias populares tais atividades continuaram a ser exercidas por uma mesma pessoa, verifica-se, na medicina acadêmica, uma progressiva distinção entre os que prescreviam e aqueles envolvidos na fabricação e na comercialização de medicamentos. Essa diferenciação não anulou a circularidade dos saberes acerca das substâncias que poderiam ser medicinais e o modo de usá-las. Por um lado, médicos e boticários interessavamse pela maneira como as pessoas sem formação acadêmica tratavam as doenças mais comuns de determinada região, assim como pelas substâncias usadas para esse fim. Por outro lado, alguns curadores populares faziam uso de conhecimentos médicos acadêmicos. ${ }^{2}$

Poucos são os estudos sobre a história do exercício farmacêutico, apesar de sua importância. A maior parte é anterior à década de 1960 e restringe-se a descrever a progressiva evolução da farmácia. ${ }^{3}$ Especificamente sobre o contexto baiano, nota-se uma lacuna, embora se verifique uma crescente produção acerca de temas relacionados à história da saúde. ${ }^{4}$ Nesse sentido, ao abordar o tema do exercício farmacêutico na província da Bahia no final do século XIX, alinhamo-nos à parte da historiografia que tem procurado ampliar o entendimento sobre a história da saúde com a sua análise em contextos diferentes da capital do Império. ${ }^{5}$ A documentação da Inspetoria de Higiene da Bahia sobre o exercício da farmácia e a legislação coetânea sobre o tema, acrescidas de documentos sobre farmacêuticos da capital do Império, propiciaram esta análise preliminar que considera a província no contexto do Brasil oitocentista.

Durante a segunda metade do século XIX, a associação farmacêutica brasileira mais importante foi o Instituto Farmacêutico do Rio de Janeiro (Santos Filho, 1991, p.372), que fez publicar, em 1877, a divulgação de um congresso, por meio da qual expunha a situação do exercício farmacêutico no Brasil. ${ }^{6}$

Congresso Farmacêutico do Brasil - Circular - A indiferença e máxima desconsideração que no Brasil se vota a tudo que tem relação com a classe farmacêutica; 
O desânimo a que essa infeliz classe se tem deixado chegar, em detrimento de seus próprios interesses, da ciência e da saúde pública;

A facilidade com que se contrariam direitos adquiridos e a ação de uma classe cujos foros se derivam da ciência;

A opressão que leva essa mesma classe a abandonar seus arraiais para filiar-se em outras profissões; ...

A não menos necessidade da criação de uma escola de farmácia, para estabelecer a autonomia do farmacêutico: são razões que justificam a oportunidade da convocação de um congresso farmacêutico, destinado, principalmente, a tomar conhecimento das anteriores proposições e a prover do remédio em competência e autoridades, as múltiplas dificuldades e embaraços que aniquilaram a classe e abastardam a profissão.

Neste propósito, pois, o primeiro dos abaixo assinados propôs a convocação daquele congresso, cuja reunião inicial deve ter lugar no dia 27 do corrente mês, ao meio dia, no edifício da rua São José n. 68.

Sendo abraçada pelos outros signatários esta idéia, são convidados todos os farmacêuticos que estejam legalmente habilitados por alguma das Faculdades do Império; a comparecerem no lugar e hora indicados, para constituírem o referido congresso, que funcionará com qualquer número.

Farmacêuticos Eduardo Julio Janvrot - Antonio Joaquim Teixeira de Azevedo - Augusto César Diogo - Francisco Maria de Mello Oliveira - Cândido Brandão de Souza Barros Fortunato Raimundo de Oliveira (Gazeta de Notícias, 22 maio 1877).

Ao mesmo tempo em que se identifica um esforço para mobilizar os farmacêuticos em torno de reivindicações, as reclamações dos profissionais reunidos no Instituto Farmacêutico traçavam um quadro desanimador do exercício farmacêutico na capital do Império, no último quartel do século XIX. Diante disso, procuramos investigar o exercício farmacêutico em uma província distante da capital: a província da Bahia. Ali se desenvolveu um curso de farmácia da Faculdade de Medicina, assim como na do Rio de Janeiro, ambas criadas em 1832.

Embora muitos aprendessem com farmacêuticos mais experientes ou em escolas independentes das faculdades de medicina, apenas estas podiam conceder autorização para o exercício da farmácia. Nas faculdades, o curso médico era priorizado, pois tinha duração de seis anos, enquanto o de farmácia, de três. Além disso, as disciplinas do curso de farmácia eram as mesmas freqüentadas pelos alunos de medicina, cerceando um tanto o desenvolvimento de uma identidade, por parte de professores e estudantes, em torno da profissão.

As mudanças e persistências na legislação e a sua execução local, a relação dos farmacêuticos com as autoridades, os médicos e aqueles que atuavam ilegalmente fabricando e vendendo remédios sem autorização são alguns dos aspectos que analisamos a seguir.

\section{A delimitação das atividades dos boticários}

O exercício da farmácia e o funcionamento das boticas foram objeto de preocupação das autoridades governamentais, como se percebe na legislação construída ao longo do século XIX sobre as artes de curar e a saúde pública. O regimento da Fisicatura-mor, de 1810, já destacava a regulamentação e fiscalização das boticas e dos boticários. ${ }^{7}$ Além de 
conferir se o boticário tinha carta, verificava-se, no caso de ele ter botica, se havia a licença, seus instrumentos e o acondicionamento e conservação das drogas.

Nas devassas que deveriam ser empreendidas pelo menos uma vez por ano onde os empregados da Fisicatura-mor conseguissem chegar, era necessário verificar se os boticários:

substituem uns remédios por outros sem autoridade de quem os receitou; se aviam receitas de medicina passadas por pessoas ilegítimas; se vendem remédios de segredo sem licença, e taxa do Físico-mor do Reino; se têm parceria com algum médico, ou cirurgião; se são prontos no aviamento das receitas a qualquer hora, se costumam desamparar a botica, deixando nela aprendizes ou escravos, que vendam remédios; se se intrometem a curar, ainda que seja pelas receitas que vão a sua botica; se algum médico ou cirurgião, que substitui a falta de médico, receita em latim, ou em breves; se obrigam aos enfermos a aviarem suas receitas em botica determinada; se receitam medicamentos de composições com nomes desconhecidos para serem entendidos somente por algum boticário; se há quem venda, e faça remédios em sua casa sem título legítimo (alvará de 22 jan.1810).

Com o intuito de tornar tal atividade específica de um grupo com formação própria, ao longo dos anos foram publicadas normas contemplando questões semelhantes, embora de forma mais detalhada.

O regulamento da Junta Central de Higiene Pública, publicado em 29 de setembro de 1851, reafirmava os pontos citados do regimento da Fisicatura-mor, desdobrando-os e acrescentando regras de conduta. As mudanças buscavam acompanhar as transformações no mercado de medicamentos de meados do Oitocentos, quando se constata um aumento do número de boticas, boticários e consumidores em relação às primeiras décadas daquele século.

Destacava-se, assim, a proibição de o médico estabelecer sociedade com algum boticário e "impor aos doentes a condição de comprar os remédios em certa e determinada botica". Também detalhavam-se aspectos relativos à clareza de uma receita, que deveria ser "em português, e ... por extenso as formulas dos remédios, ou sejam próprias ou alheias, com os nomes e doses das substâncias que entram na composição dos mesmos remédios, sem abreviaturas, sinais, nem algarismos". Além disso, as receitas deveriam apresentar "o modo por que se deve fazer uso do remédio e especialmente se interna ou externamente" e identificar "o nome do dono da casa, e, não havendo inconveniente, a pessoa a quem é destinado, assim como o dia, mês e ano em que são escritas". Ressaltava-se que os boticários não deveriam preparar "receita que não esteja assinada por Facultativo matriculado" nem poderiam "alterar, nem substituir os medicamentos ou as substâncias que forem prescritas para a sua composição". As boticas deveriam ser administradas por boticários matriculados ou oficiais aprovados pelas escolas de medicina. Ademais, os boticários ou droguistas não poderiam abandonar suas boticas ou drogarias sem que deixassem em seu lugar pessoa habilitada para fazer suas vezes. Se algum erro fosse cometido em sua ausência, por troca de substância ou alteração de dose, e resultasse em dano, incorriam nas penas da lei.

Em meio aos demais assuntos - administração, exercício da medicina, cemitérios, portos, vacinação -, mais de um terço dos artigos do regulamento de 1851 era dedicado à fabricação e venda de medicamentos. Assim, embora se identifiquem normas mais detalhadas, muito do regimento da Fisicatura-mor foi retomado no regulamento da Junta Central de Higiene 
Pública. Tratava-se de um ofício muito visado pelas autoridades sanitárias - constituídas em seus cargos maiores por médicos -, porque se considerava que o sucesso do tratamento prescrito dependia também da competência dos boticários para manipular os medicamentos.

A preocupação voltava-se tanto para o problema de pessoas sem formação dirigirem boticas quanto para a associação entre médicos e boticários. Havia, no entanto, uma grande dificuldade em se colocar a lei em prática. Em 1865 o inspetor de saúde pública da Bahia enviou um relatório para a Junta Central de Higiene Pública justificando a falta de dados sobre as artes de curar, pois "como V.Sa. não ignora, nos diversos centros de população desta Província não há autoridades" que possam informar sobre a situação no interior baiano (Apeb, maço 5.348).

Além disso, as condições enfrentadas pelos habitantes da província tornavam a fiscalização sobre o cumprimento da lei uma preocupação secundária por parte do governo. Entre os últimos anos da década de 1850 até 1861, a Bahia enfrentou uma terrível seca, que agravou o problema de carestia vivido pelos baianos ao longo do século XIX. A grande concentração de riquezas intensificava o quadro de penúria enfrentado pelas camadas mais pobres (Reis, Aguiar, 1996). Testemunhas apontavam, no início da década de 1860, para a calamidade vivenciada no período: "Por toda a Estrada fui encontrando a maior desgraça e miséria em famílias emigradas do Sertão", enfatizando-se que "o pai e a esposa, o filho, a viúva e o órfão que estiverem nas garras da fome" agradeceriam o envio de víveres e mantimentos, além da assistência médica (Relatório de 1861 do delegado de saúde ao inspetor de saúde; Apeb, maço 5.348).

Assim como se observou em outros contextos, grupos como médicos e farmacêuticos costumavam fazer caridade durante os flagelos e divulgar o seu ato, buscando reconhecimento social. ${ }^{8}$ Provavelmente foi nesse sentido que se posicionou um farmacêutico baiano ao informar à Presidência da província, em 1860, quando se enfrentava uma grande carestia, que iria manipular medicamentos "e medicar gratuitamente os pobres, não querendo outra recompensa mais que o prazer de aliviar a existência, já tão custosa dessa parte da população que, hoje, além da fome, se aterra com a idéia de adoecer, pois além de faltar muitos medicamentos, os que há são por preços exagerados" (Apeb, maço 5.348).

Diante da miséria e necessidade de ajuda, o governo não poderia recusar auxílio oferecido por farmacêuticos, estivessem ou não exercendo suas atividades de acordo com a lei. Contudo, mesmo em momentos nos quais a sociedade baiana não enfrentava alguma calamidade, a não observância à lei parece ter-se tornado constante. Em correspondência entre o inspetor da Saúde da Bahia e o presidente da província, em 1879, o primeiro admitia que vários artigos do regulamento da Junta de Higiene Pública, de 1851, haviam "gradualmente caído em desuso, ou são sofismados ou iludidos pelos infratores da lei que as estabelece".

O inspetor não se privou de apontar a necessidade de uma medida geral, que compreenda a todos os infratores das disposições de Regulamento de
29 de Setembro de 1851 quer tenham assento na Faculdade de Medicina, ou façam parte do
Conselho Administrativo da Sociedade Médico-Farmacêutica de Beneficência, quer sejam
donos de lojas de perfumarias; porque não pode a Inspeção da Saúde Pública procurar punir
apenas os pequenos culpados, deixando incólumes lá os grandes e privilegiados; porque a lei,
na forma da Constituição do Império, deve ser igual para todos, quer castigue, quer proteja; 
não pode esta Inspetoria começar a campanha sem contar com a desafronta da lei, de modo temeroso para ela (Apeb, maço 5.348).

O inspetor concluía a questão lamentando que a congregação da Faculdade de Medicina "restringisse as amplas prerrogativas suas ao mesquinho assunto de venda de remédios fora das boticas". Deixava claro, no entanto, que continuava reprimindo algumas irregularidades, contando com a solicitude do chefe de polícia (Apeb, maço 5.348).

O discurso parecia ser contrário às práticas de uma sociedade paternalista, em que as relações sociais eram permeadas por laços de dependências pessoais (Graham, 1990), mas o tom ácido de seu comentário constituía também uma resposta à solicitação que a congregação da Faculdade de Medicina da Bahia encaminhou ao presidente da província. Esta chamava a atenção para uma falha do inspetor, ao pedir que "por intermédio da autoridade competente se dignasse proibir eficazmente que nas lojas de perfumarias, e casas não autorizadas se vendam preparados farmacêuticos de qualquer ordem e muito particularmente os de ingredientes desconhecidos e apregoados, abusando-se da credulidade pública, como meios capazes e infalíveis para curar um número considerável de moléstias" (Apeb, maço 5.348).

A despeito de inúmeros outros problemas relacionados à seca e à carestia, a congregação da Faculdade de Medicina da Bahia incomodava-se sobretudo com a fabricação e venda de remédios sem autorização. Sugerimos que essa preocupação relacionava-se não só à saúde da população, mas também ao exercício ilegal da medicina, menos talvez do que ao da farmácia. Desde que os curandeiros ou terapeutas não acadêmicos deixaram de receber autorizações formais para atuar, muitos passaram a ser identificados com a produção e venda de remédios. Quiçá o mais grave para os membros da congregação tenha sido o fato de que antes de produzir e vender medicamentos essas pessoas diagnosticavam e prescreviam - espaço que deveria ser exclusivo dos médicos.

A precedência dos médicos em relação aos farmacêuticos pode ser percebida no discurso destes para reivindicar suas prerrogativas, no qual se procurava chamar a atenção para o vínculo entre o desrespeito ao exercício farmacêutico e ao exercício médico:

Os farmacêuticos abaixo afirmados, zelosos das prerrogativas que lhe concede a Lei, e desejando somente o império dela, especialmente tratando-se de tão grave assunto quanto a saúde pública, e o crédito daqueles que são os executores das ordens dos médicos, medianeiros entre a natureza e Deus, no grande problema da vida, não podem permitir, com prejuízo geral e menoscabo à sua classe, além de real prejuízo, que siga por diante o abuso de, sem titulo, e talvez sem habilidades nem observância das prescrições legais, ... existirem Farmácias, sem quem as represente, e sem que tenham cumprido o que é de direito (carta dos farmacêuticos Euclides Caldas, José de Calazans, Ismael da Silva, Francisco Ribeiro e Manoel Ribeiro ao presidente da província, 9 dez. 1885; Apeb, maço 5358).

Destacavam ainda que não se tratava apenas de fiscalizar se o responsável por uma farmácia possuía ou não diploma de farmacêutico, mas também de coibir o charlatanismo, evitando "que se lance no seio da população que procura a vida pelo remédio, a morte pela droga falsificada!" (Apeb, maço 5.358).

Além da preocupação com a saúde pública, os farmacêuticos acima se dirigiram ao inspetor e ao presidente da província para denunciar que, em Salvador, uma farmácia 
aberta na rua de São Pedro número dois não obedecia às determinações de diversos artigos do regimento de 19 de janeiro de 1882, que substituiu o de 1851.

Apesar de manter a proporção de artigos voltados para a regulamentação da fabricação e venda de medicamentos, estes se apresentavam muito mais detalhados e acrescidos de tópicos que pretendiam responder às novas situações encontradas na década de 1880 . Assim, verificamos em 1882 artigos quase idênticos, proibindo médicos de preparar e vender medicamentos, estabelecer sociedade com farmacêutico ou droguista e impor aos doentes a condição de comprar os remédios em determinada botica ou drogaria. Destacava-se que os médicos não podiam ter consultório em botica ou drogaria (art.49, 71).

Outro artigo que mereceu ressalva dizia respeito à necessidade de os farmacêuticos fornecerem medicamentos somente mediante receitas assinadas por médicos. Haveria uma tabela daqueles "de uso ordinário e inofensivo", que poderiam ser vendidos a pedido do comprador. Mantinha-se a ressalva de que o farmacêutico não poderia alterar as fórmulas ou substituir os medicamentos prescritos. Mas destacava-se, com ênfase maior, que o exercício simultâneo da medicina e da farmácia era expressamente proibido, ainda que o médico possuísse o título de farmacêutico (art.70). Deixava-se claro que, se o médico estivesse estabelecido onde não houvesse botica, poderia fornecer os medicamentos necessários ao tratamento de seus doentes caso eles residissem a seis quilômetros da botica mais próxima; ainda assim ele não poderia ter botica aberta ao público.

No regulamento de 1882 declarava-se que, para suprirem a sua falta em algum impedimento temporário, os farmacêuticos poderiam ter oficiais de farmácia competentemente aprovados, segundo instruções que ainda seriam publicadas. Mesmo antes de resolver a questão dos oficiais de farmácia, afirmava-se que não seriam mais concedidas licenças para práticos terem boticas. E se os habitantes de algum lugar onde não houvesse botica reclamassem, a respectiva Câmara Municipal providenciaria para que ali se estabelecesse um farmacêutico legalmente habilitado (art.73).

Dessa forma, as novidades acerca da prática da farmácia estavam relacionadas ao aumento do número de farmacêuticos, o que permitia a interdição de médicos, por um lado, e de práticos, por outro, ao exercício dessa atividade.

\section{A lei no dia-a-dia}

A despeito de todas as normas elaboradas e reforçadas ao longo de sucessivos regulamentos, o médico Julio Gama exercia a medicina vinculado à Farmácia Gama, situada na Praça do Mercado número 17, em Lençóis, na década de 1880. O estabelecimento era dirigido por Manoel Magiano Pinto, que não possuía diploma. Até a chegada do farmacêutico Archimimo da Fonseca era a única farmácia na cidade.

Vários testemunhos, apresentados pelo próprio denunciante, dão conta de que doutor Julio tratava da saúde de muitas famílias da cidade, prescrevendo remédios para serem aviados na farmácia que levava o seu sobrenome. Portanto, tendo chegado havia pouco tempo na cidade, parece não ter sido muito ponderada a atitude de Archimimo de pedir à Câmara Municipal que fechasse a Farmácia Gama e, menos ainda, aproveitar a mesma 
petição para solicitar que "outras casas que existem na mesma praça não continuem a vender medicamentos e preparados que gozem de proponentes medicinais" (Apeb, maço 5.358).

No final de agosto de 1884, Archimino denunciou que o doutor Julio, "em detrimento do peticionário, além da profissão médica exerce também a de farmacêutico, tendo farmácia aberta ao público para onde encaminha seus doentes, contra o que determina a Lei, sendo muito para notar, que suas formulas não são transcritas in extenso ...". Requereu ainda que se proibisse Magiano de continuar a exercer ilegalmente a profissão farmacêutica (Apeb, maço 5.358).

A fim de resolver todos os problemas, pedia Archimino ao presidente da Câmara que convocasse os vereadores para deferirem a seu favor. A convocação, contudo, não foi feita, e um mês depois o suplicante se dirigia ao inspetor de saúde pública e ao presidente da província, que recomendaram às autoridades de Lençóis que "pessoas não autorizadas" fossem impedidas de cometer tais infrações da lei. Em suas últimas petições, Archimimo havia concentrado suas denúncias em Magiano e não se referiu mais às atividades do doutor Julio, o que sugere ser a atuação de um médico mais difícil de contestar do que a de um prático, ainda que houvesse violação da lei (Apeb, maço 5.358).

Como os períodos anteriores, a década de 1880 também foi tumultuada por secas e epidemias que causavam ainda mais tensões nas relações sociais já afetadas em época de crise do escravismo. Mudanças sucessivas nas leis parecem indicar tentativas de restabelecer a ordem. Desse modo, apenas quatro anos depois de publicado o decreto de 1882, o serviço sanitário do Império foi reorganizado, na reforma Mamoré (3 fev. 1886), que elaborou novo regulamento, bem mais extenso do que os anteriores. O órgão responsável pela saúde pública passou a ser denominado Inspetoria Geral de Higiene, sendo instituído um Conselho Superior de Saúde Pública com a função de opinar sobre questões de higiene e salubridade em geral. Mais uma vez, reformulações na estrutura formal e medidas normativas foram empreendidas para tentar resolver os problemas de saúde pública, sem se verificarem mudanças efetivas nas condições sanitárias do país (Luz, 1982; Costa, 2004).

Em geral, as determinações sobre o exercício da farmácia se mantiveram, notando-se que a permissão para que o médico fornecesse medicamentos aos doentes que residissem distantes de farmácias passou de seis para três quilômetros (art.48) - uma provável tentativa de adequação ao cotidiano da população, que passava por mudanças causadas, em grande parte, pelo adensamento urbano.

Destaca-se, porém, uma importante modificação entre o decreto de 1882 e a reforma Mamoré, de 1886, quanto à exclusividade de manipular medicamentos conferida aos farmacêuticos. Com a legislação de 1886 permitiu-se novamente a concessão de licenças a práticos para abrirem farmácia (art.65, 66). Contudo, ressaltava-se que isso só seria consentido depois de se certificarem de que nenhum farmacêutico teria interesse em estabelecer uma farmácia no mesmo local.

A permanência de artigos com o mesmo sentido nos sucessivos regulamentos que tratavam do exercício das artes de curar não poupava os farmacêuticos de problemas, cada vez que se publicava uma nova legislação. Assim como vários outros colegas, Euclides Caldas, dono da Farmácia Caldas, situada na rua Carlos Gomes, viu-se intimado, em 1889, a tirar licença em 24 horas para continuar com o seu estabelecimento aberto. Formado 
pela Faculdade de Medicina da Bahia, matriculado na Junta de Higiene e com farmácia aberta desde 1865, por mais de um ano Euclides esteve às voltas com recursos e trâmites burocráticos com argumentos contra a ação do inspetor de higiene. Ao recorrer à Presidência da província, explicava que o regulamento em vigor no tempo da instalação da farmácia era o de 1851, cujas licenças não seriam um "tributo orçamentário; eram antes o meio de consagração da capacidade profissional reconhecida pelos exames que as precediam". Além disso, segundo o próprio Euclides, a farmácia vinha recebendo confiança de distintos clínicos da capital e do público. A Inspetoria não poderia, portanto, ignorar todo o "precedente que legitima a existência da farmácia em questão". Apesar da demora, o recurso foi deferido (Apeb, maço 5.358).

\section{Considerações finais}

A conformação das atividades de farmacêutico pode ser acompanhada nas repetidas exigências acerca das condições mínimas de trabalho: as boticas (assim denominadas até o regulamento de 1882) ou farmácias (a partir do regulamento de 1886) só poderiam funcionar devidamente providas de drogas, vasilhames, utensílios e livros, de acordo com as tabelas aprovadas pelo governo e a farmacopéia em uso. Em 1851, a farmacopéia francesa substituiu a de Portugal, existindo porém a possibilidade de serem usadas outras farmacopéias para atender às prescrições dos médicos. ${ }^{9}$ Ao mesmo tempo, observa-se um conflituoso processo de delimitação de prerrogativas e responsabilidades, destacando-se a posição subalterna assumida pelos farmacêuticos diante dos médicos. Essa se relacionava com a vinculação do curso de farmácia à Faculdade de Medicina, o que era identificado como problema, conforme demonstra o convite-manifesto para o congresso farmacêutico no Rio de Janeiro.

A pressão dos farmacêuticos junto aos políticos para a criação de um curso autônomo e em prol de prerrogativas legais que garantissem efetivamente a exclusividade de suas atividades provavelmente foi limitada pela permanência dos práticos e de seu direito a ter botica aberta. $\mathrm{O}$ fato de que indivíduos sem formação acadêmica pudessem desempenhar atividades de farmacêuticos e possuir uma farmácia deve ter contribuído para que muitos não tenham se dedicado à formação acadêmica, para a qual era necessário ter investido anteriormente em educação formal, além de custear o curso. Ademais, por muito tempo depois da criação do curso farmacêutico, em 1832, o aluno continuava a obter boa parte dos conhecimentos em farmácias particulares, das quais receberia um atestado de haver praticado a arte (Albuquerque, 1932). Essa forma de aprendizado e de reconhecimento oficial de sua habilidade não era muito diferente do que se passava no tempo da Fisicaturamor, nas primeiras décadas do século XIX.

\section{AGRADECIMENTOS}

As autoras agradecem ao editor de História, Ciências, Saúde - Manguinhos, Jaime Benchimol, e aos pareceristas deste artigo as sugestões enriquecedoras. 


\section{NOTAS}

${ }^{1}$ Desenvolvido no Instituto de Saúde Coletiva da UFBA em parceria com a Casa de Oswaldo Cruz/ Fundação Oswaldo Cruz. Participaram da pesquisa Elizabete Vianna Delamarque e Joel Nolasco Queiroz de Cerqueira e Silva.

${ }^{2}$ Essa questão, entretanto, não é objeto deste artigo. Sobre o tema, ver Marques, 1999 e Ribeiro, 1997, que estudam o assunto no que se refere ao século XVIII; e Pimenta, 2004a e Figueiredo, 2002, para o século XIX. ${ }^{3}$ Ver, por exemplo, Carvalho, 1924, 1952, Oliveira, 1956, Rangel Filho, 1952, Votta, 1965 e Santos Filho, 1991. ${ }^{4}$ Em uma perspectiva mais ampla da história da saúde, destacamos trabalhos importantes como o de Reis, 1991, David, 1996, Barreto, 2005, Ferreira Filho, 2003 e Souza, jan.-abr. 2005.

${ }^{5}$ Ver, por exemplo, Barbosa, 2004, Beltrão, 2000 e Diniz, 2003.

${ }^{6}$ Sobre a história da farmácia no Rio de Janeiro da segunda metade do século XIX, ver Velloso, 2007.

${ }^{7}$ Órgão criado em 1808, após a instalação da corte portuguesa no Brasil. Com sede no Rio de Janeiro, era responsável pela regulamentação e fiscalização de todas as artes de curar e atividades relacionadas.

${ }^{8}$ Observa-se esse comportamento, por exemplo, durante a epidemia de cólera no Rio de Janeiro em 1855 (Pimenta, 2004b).

${ }^{9}$ A primeira farmacopéia oficial elaborada no país foi a do estado de São Paulo em 1917. A primeira publicação da Farmacopéia Brasileira ou Farmacopéia dos Estados Unidos do Brasil ocorreu em 1926 (dec.17.509), com determinação de seu uso obrigatório em 1929.

\section{REFERÊNCIAS}

ALBUQUERQUE, Anselmo de. O centenário médico de 1932. Revista do Instituto Geográfico e Histórico da Bahia, Salvador, v.58, p.443-453. 1932.

APEB.

Governo da Província, série Saúde (1860-1886), maço 5.348 (Arquivo Público do Estado da Bahia).

APEB.

Governo Provincial, série Saúde - Farmácia (1878-1889), maço 5.358 (Arquivo Público do Estado da Bahia).

BARBOSA, Francisco C.J.

As doenças viram notícia: imprensa e epidemias na segunda metade do século XIX. In: Nascimento, Dilene; Carvalho, Diana (Org.). Uma história brasileira das doenças. Brasília: Paralelo 15. p.76-90. 2004.

BARRETO, Renilda. A medicina luso-brasileira: instituições, médicos e populações enfermas em Salvador e Lisboa (1808 1851). Tese (Doutorado) - Programa de Pós-graduação em História das Ciências e da Saúde da Casa de Oswaldo Cruz, Fundação Oswaldo Cruz, Rio de Janeiro. 2005.

BELTRÃO, Jane Felipe.

A arte de curar dos profissionais de saúde popular em tempo de cólera: Grão-Pará do século XIX. História, Ciências, SaúdeManguinhos, Rio de Janeiro, v.6, supl., p.833-866. 2000.
CARVALHO, José Coriolano de.

O centenário da imprensa farmacêutica no Brasil. S.l.: s.n. 1952.

CARVALHO, José Coriolano de.

Da farmácia: origem e evolução - contribuição do estudo da farmácia no Brasil. Rio de Janeiro: Typ. Jornal do Commercio. 1924.

COSTA, Ediná.

Vigilância sanitária: proteção e defesa da saúde. São Paulo: Sociedade Brasileira de Vigilância de Medicamentos. 2004.

DAVID, Onildo.

O inimigo invisível: epidemia na Bahia no século XIX. Salvador: Edufba. 1996.

DINIZ, Ariosvaldo.

As artes de curar nos tempos do cólera - Recife, 1856. In: Chalhoub, Sidney et al. (Org.). Artes $e$ ofícios de curar no Brasil. Campinas: Ed. Unicamp. p.355-385. 2003.

FERREIRA FILHO, Alberto Heráclito. Quem pariu e bateu, que balance!: mundos femininos, maternidade e pobreza - Salvador, 1890-1940. Salvador: Edufba. 2003.

FIGUEIREDO, Betânia.

$A$ arte de curar: cirurgiões, médicos, boticários e curandeiros no século XIX em Minas Gerais. Rio de Janeiro: Vício de Leitura. 2002.

GRAHAM, Richard.

Patronage and politics in nineteenth-century

Brazil. Stanford: Stanford University Press. 1990. 
LUZ, Madel.

Medicina e ordem política brasileira: políticas e instituições de saúde (1850-1930). Rio de Janeiro: Graal. 1982.

MARQUES, Vera Beltrão.

Natureza em boiões: medicinas e boticários no Brasil setecentista. Campinas: Ed. Unicamp. 1999.

OLIVEIRA, Abel de.

Histórico da farmacopéia brasileira. Revista da Academia Fluminense de Letras, Niterói, v.9, separata. 1956.

PIMENTA, Tânia Salgado.

Transformações no exercício das artes de curar no Rio de Janeiro durante a primeira metade do Oitocentos. História, Ciência e Saúde Manguinhos, Rio de Janeiro, v.11, supl.1, p.67-92. 2004a.

PIMENTA, Tânia Salgado.

Doses infinitesimais contra a epidemia de cólera em 1855. In: Nascimento, Dilene; Carvalho, Diana (Org.). Uma história brasileira das doenças. Brasília: Paralelo 15. p.31-51. 2004b.

PIMENTA, Tânia Salgado.

Barbeiros-sangradores e curandeiros no Brasil

(1808-1828). História, Ciências, Saúde -

Manguinhos, Rio de Janeiro, v.5, n.2, p.349-375.

1998.

RANGEL FILHO, Antenor.

As sociedades, os congressos e as convenções farmacêuticas no Brasil. Rio de Janeiro: Jornal do Commercio. 1952.
REIS, João J.

A morte é uma festa. São Paulo: Companhia das Letras. 1991.

REIS, João J.; AGUIAR, Márcia G.D. de.

'Carne sem osso e farinha sem caroço': o motim de 1858 contra a carestia na Bahia. Revista de História, São Paulo, n.135, p.133-160. 1996.

RIBEIRO, Márcia Moisés.

A ciência dos trópicos: a arte médica no Brasil do século XVIII. São Paulo: Hucitec. 1997.

SANTOS FILHO, Lycurgo.

História geral da medicina brasileira. São Paulo: Hucitec. 1991.

SOUZA, Christiane M.C. de.

A gripe espanhola em Salvador, 1918: cidade de becos e cortiços. História, Ciências, Saúde -

Manguinhos.Casa de Oswaldo Cruz/Fiocruz, vol.12, n.1, p.71-99. jan.-abr. 2005.

VELLOSO, Verônica.

Farmácia na Corte imperial (1851-1887): práticas e saberes. Tese (Doutorado) - Programa de Pósgraduação em História das Ciências e da Saúde da Casa de Oswaldo Cruz, Fundação Oswaldo Cruz, Rio de Janeiro. 2007.

VOTTA, Raul.

Breve história da farmácia. Rio de Janeiro: Labs Enila. 1965. 